\title{
Effects of Grape Seedlings Intercropping with Hyperaccumulators on Soil Enzyme Activity under Cadmium Stress
}

\author{
Xinxin $\mathrm{Li}^{1, \mathrm{a}}$, Lijin Lin ${ }^{2, \mathrm{~b}}$, Dan Xia ${ }^{1, \mathrm{c}}$ and Ming'an Liao ${ }^{1, \mathrm{~d}^{*}}$ \\ ${ }^{1}$ College of Horticulture, Sichuan Agricultural University, Chengdu, Sichuan, China \\ ${ }^{2}$ Institute of Pomology and Olericulture, Sichuan Agricultural University, Chengdu, Sichuan, China \\ a347319112@qq.com, 'llj800924@163.com, '1358068232@qq.com, Iman@sicau.edu.cn \\ ${ }^{*}$ Corresponding author. Xinxin Li and Lijin Lin contributed equally to this work.
}

Keywords: Intercropping; Grape; Soil Enzyme Activity; Hyperaccumulators

Abstract: The effects of intercropping with four hyperaccululator plants Galinsoga parviflora, Sigesbeckia orientalis, Solanum nigrum and Crassocephalum crepidioide on soil enzyme activity and soil organic matter of grape seedlings under cadmium $(\mathrm{Cd})$ stress were studied by a pot experiment. The results showed that intercropping with $C$. crepidioide and the monoculture had no significant differences in soil organic matter, but other treatments were higher than the monoculture. Compared to the monoculture, urease and catalase activities were increased by intercropping with $C$. crepidioide, but the activities of invertase and phosphatase were decreased. The other intercropping treatments on soil enzyme activity were higher than the monoculture, and intercropping with $S$. orientalis was the best.

\section{Introduction}

$\mathrm{Cd}$ is one of the most toxic heavy metal elements that harmful to the growth of plants and human health [1]. As a component of soil, the activity of enzyme can sensitively reflect the direction and intensity of biochemical reaction in soil [2]. The distribution of heavy metal ions in soil will affect soil enzyme activity, and it is feasible to detect soil heavy metal contamination with soil enzyme activity [3]. Intercropping can not only improve the productivity, but also improve soil environment, improve soil enzyme activity and crop absorption of nutrient elements [4]. These studies have shown that soil enzyme activity is affected by non-hyperaccumulators intercropping with hyperaccumulators [5-6]. The grape is a perennial fruit tree, which has a stronger enrichment ability of cadmium [7]. Therefore, in this study, we used four Cd hyperaccumulator plants Galinsoga parviflora [8], Sigesbeckia orientalis [9], Solanum nigrum [10], and Crassocephalum crepidioides [11] intercropping with grape seedlings of Kyoho under $\mathrm{Cd}$ stress by a pot experiment to study the effects on soil organic matter and soil enzyme activity, that could screen out which intercropping treatment significantly increase the soil enzyme activity, and provide reference for the grape production in Cd-contaminated area.

\section{Materials and Methods}

Materials. In April 2016, the seeds of four hyperaccumulator plants G. parviflora, S. orientalis, S. nigrum and $C$. crepidioides were collected from the surrounding farmland at Chengdu campus of Sichuan Agricultural University. Then, the seeds were put in the climate chamber to germination and further cultivation and transplanting. The experimental cultivar of grape is Kyoho, whose cutting seedlings were purchased from Longquanyi area seedlings base of Chengdu in May 2016. The soil for the experiment was collected from the surrounding farmland at Chengdu campus of Sichuan Agricultural University in April 2016.

Experimental Design. The experiment was conducted in Chengdu Campus of Sichuan Agricultural University from April to July 2016. In April 2016, the soil was air-dried and passed through a 6.72-mm sieve. $3 \mathrm{~kg}$ air-dried soil was weighed into each plastic pot $(21 \mathrm{~cm}$ high, $20 \mathrm{~cm}$ in diameter), soaking uniformly by $5 \mathrm{mg} \cdot \mathrm{kg}^{-1} \mathrm{Cd}$ (in the form of $\mathrm{CdCl}_{2} \cdot 2.5 \mathrm{H}_{2} \mathrm{O}$ ) solution for 4 weeks. All pots were watered each day to keep the soil moisture about $80 \%$. In May 2016 , three 
uniform-sized cutting seedlings (the shoots were about $15 \mathrm{~cm}$ ) of Kyoho grape were transplanted into pot for monoculture. Two uniform-sized seedlings (two ture leaves expanded) of each four hyperaccumulators and two grape seedlings were transplanted into each pot for intercropping. For each treatment with three replicates and the pots placed completely random. The distance between pots was $15 \mathrm{~cm}$, and the pot position exchanged aperiodically to weaken the impact of the marginal effects. The soil moisture content was maintained at $80 \%$ of field capacity until the plants were harvested.

After 60 days, the soil in the $0-5 \mathrm{~cm}$ layer of each pot was taken out, mixed and packaged in plastic bags and brought back to the laboratory and stored in a refrigerator at 4 degrees centigrade. Soil enzyme activity was determined by soil enzyme method [12] after soil $1 \mathrm{~mm}$ screening. The activity of catalase was expressed as the volume of $0.02 \mathrm{~mol} \cdot \mathrm{L}^{-1} \mathrm{KMnO}_{4}$ per gram of soil at room temperature in 30 minutes. Soil urease activity was expressed in grams $(\mathrm{mg})$ of $\mathrm{NH}^{+3}-\mathrm{N}$ per gram of soil at $37{ }^{\circ} \mathrm{C}$ for 24 hours. Soil invertase activity was expressed in the amount of glucose released per gram of soil at $37{ }^{\circ} \mathrm{C}$ for 24 hours. Soil phosphatase was expressed in grams of phenol per gram of soil.

Statistical Analyses. The data were analyzed by SPSS 20.0, and were plotted by Excel.

\section{Results and Discussion}

Soil Organic Matter. Compared with the monoculture, intercropping with $S$. orientalis, $S$. nigrum and $G$. parviflora, soil mass fraction increased slightly (Fig. 1), which incresed by $2.85 \%$ $(p<0.05), 2.14 \%(p<0.05)$ and $0.71 \%(p<0.05)$, separately. However, the soil organic matter had no significant differences between intercropping with C. crepidioide and the monoculture.

Soil Catalase Activity. Compared with the monoculture, intercropping treatments increased the activities of catalase (Fig. 2), which increased by $1.96 \%(p<0.05), 5.88 \%(p<0.05), 2.94 \%$ ( $p<$ $0.05)$ and $0.98 \%(p<0.05)$, following the order. Intercropping with $S$. orientalis was the highest. So, under the stress of $\mathrm{Cd}$, intercropping treatments can improve the soil catalase activity.

Soil Invertase Activity. The soil invertase activities were ranked in the following order: intercropping with $S$. orientalis > intercropping with $S$. nigrum > intercropping with G. parviflora > monoculture > intercropping with $C$. crepidioides (Fig. 3). Under the stress of $\mathrm{Cd}$, compared with the monoculture, intercropping with $C$. crepidioide decreased the soil invertase activity by $1.00 \%(p$ $<0.05$ ). But, intercropping with $S$. orientalis increased the soil invertase activity by $10.02 \%$ ( $p<$ $0.05)$.

Soil Urease Activity. Compared with the monoculture, all intercropping treatments increased the soil urease activity slightly (Fig. 4), and intercropping with $S$. orientalis was the highest, $S$. nigrum followed, which increased by $3.17 \%(p<0.05)$ and $1.74 \%(p<0.05)$, separately.

Soil Phosphatase Activity. The change of soil phosphatase activity was consistent with the soil catalase activity under the intercropping treatments (Fig. 5). The soil phosphatase activity of intercropping with $C$. crepidioide bellowed the monoculture, but, other treatments were higher than the monoculture, and intercropping with S. orientalis was the highest, which increased by $11.47 \%$ $(p>0.05)$. 


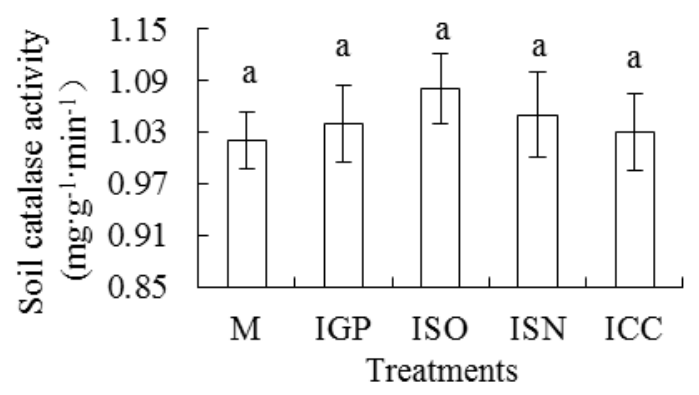

Fig. 2 Soil catalase activity. Different lowercase letters indicate significant differences based on one-way analysis of variance in SPSS 20.0 followed by the least significant difference test $(p<0.05) . \mathrm{M}=$ monoculture, IGP = intercropping with $G$. parviflora, $\mathrm{ISO}=$ intercropping with $S$. orientalis, ISN = intercropping with $S$. nigrum, ICC $=$ intercropping with $C$. crepidioides.

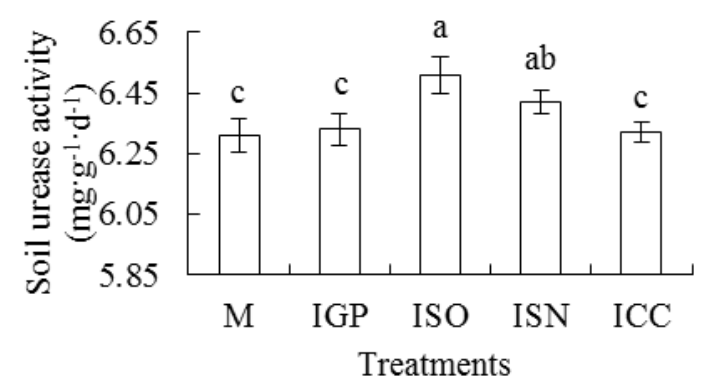

Fig. 4 Soil urease activity. Different lowercase letters indicate significant differences based on one-way analysis of variance in SPSS 20.0 followed by the least significant difference test $(p<0.05) . \quad \mathrm{M}=$ monoculture, $\mathrm{I} G P=$ intercropping with $G$. parviflora, ISO = intercropping with $S$. orientalis, ISN = intercropping with $S$. nigrum, ICC= intercropping with $C$. crepidioides.

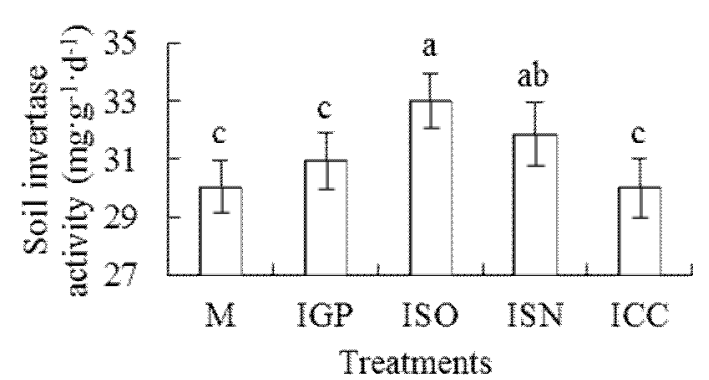

Fig. 3 Soil invertase activity. Different lowercase letters indicate significant differences based on one-way analysis of variance in SPSS 20.0 followed by the least significant difference test $(p<0.05) . \mathbf{M}=$ monoculture, $\mathrm{I} G P=$ intercropping with $G$. parviflora, $\mathrm{ISO}=$ intercropping with $S$. orientalis, ISN = intercropping with $S$. nigrum, $\mathrm{ICC}=$ intercropping with $C$. crepidioides.

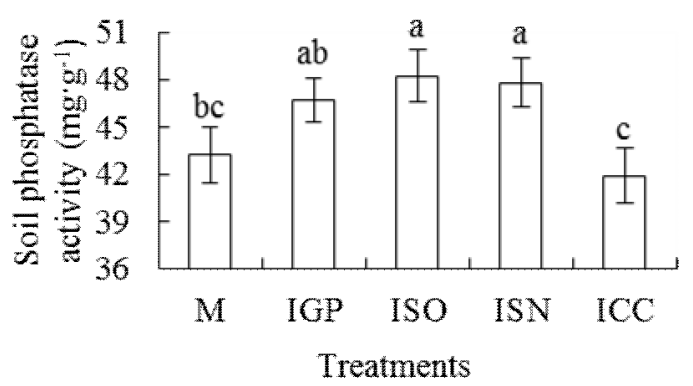

Fig. 5 Soil phosphatase activity. Different lowercase letters indicate significant differences based on one-way analysis of variance in SPSS 20.0 followed by the least significant difference test $(p<0.05) . \quad \mathrm{M}=$ monoculture, IGP = intercropping with $G$. parviflora, $\mathrm{ISO}=$ intercropping with $S$. orientalis, ISN = intercropping with $S$. nigrum, ICC $=$ intercropping with $C$. crepidioides.

\section{Conclusions}

Under the stress of $\mathrm{Cd}$, there were no significant differences in the soil organic matter between intercropping with $C$. crepidioide and the monoculture. However, other treatments were higher than the monoculture. It can improve the microbial environment of cadmium contaminated soil, but it needs to be further studied. Intercropping with $C$. crepidioide only improved the activities of soil catalase and urease. However, other intercropping treatments improved the activities of urease, invertase, catalase and phosphatase in the soil. Therefore, intercropping treatments had improvement effects on soil enzyme activity, and intercropping with $S$. orientalis was the best, $S$. nigrum followed.

\section{Acknowledgements}

This work was financially supported by the Application Infrastructure Project of Science and Technology Department of Sichuan Province (2016JY0258). 


\section{References}

[1] L. Li, J.B. Zhang, W.N. Huang: Journal of Ecology Vol. 20 (2000), p 514.

[2] W.X. He, Y. Zhao: Soil and Environment Vol. 9 (2000), p 139.

[3] X. Liu, S.Q. Liu: Journal of Agricultural University of Hebei Vol. 25 (2002), p 33.

[4] J. Shi, T.Y. Huang, X.D. Zhu, L.J. Lin, M.A. Liao: Shaanxi Journal of Agricultural Sciences Vol. 61 (2015), p 28.

[5] J. Cheng, M.A. Liao, L.J. Lin, Y.M. Luo: Journal of North China Agriculture Vol. 21 (2013), p. 1565.

[6] D.Y. Yang, L.J. Lin, X. Zhang, L. Luo, M.A. Liao, J. He: Bulletin of Soil and Water Conservation Vol. 35 (2015), p. 73.

[7] X.J. Shao, H.Q. Yang, H.T. Qiao, L. Zhang, S.Z. You: Chinese Journal of Applied Ecology Vol. 20 (2009), p. 1390.

[8] L.J. Lin, Q. Jin, Y.J. Liu, B. Ning, M.A. Liao, L. Luo: Environmental Toxicology and Chemistry Vol. 33 (2014), p. 2422.

[9] X.X. Xu, Y.Y. Dong, Y.L. Deng, Q.L. Huo, S.R. Zhang, Y.L. Pu: Journal of Agro-Environment Science Vol. 35 (2016), p. 1672.

[10] S.H. Wei, Q.X. Zhou, X. Wang: Environmental Science Vol. 26 (2005), p. 167.

[11] Y. Li, S.R. Zhang, S.Q. Zhang, L.J. Deng, T. Li, X.X. Xu: Journal of Agro-Environment Science Vol. 31 (2012), p. 1296.

[12] L.K. Zhou, Z.M. Zhang: Chinese Journal of Soil Science Vol. 5 (1980), p. 37. 